\title{
Coordination of lipid droplet-associated proteins during the transition period of Holstein dairy cows
}

\author{
D. A. Koltes and D. M. Spurlock ${ }^{1}$ \\ Department of Animal Science, lowa State University, Ames 50011
}

\begin{abstract}
Dairy cows often experience negative energy balance with the onset of lactation, and severe or prolonged negative energy balance can contribute to declines in overall fitness. Energy stores, in the form of adipose tissue triacylglycerides, are mobilized during times of energy deficit, and recent research has implicated several proteins associated with the lipid droplet as lipolytic regulators. The objective of this study was to determine if these novel proteins associated with lipolytic regulation are altered with the changing metabolic demands of lactation. Weekly blood samples were collected from 26 Holstein cows from $21 \mathrm{~d}$ before expected parturition through $28 \mathrm{~d}$ postpartum, and again at $150 \mathrm{~d}$ postpartum. Serum nonesterified fatty acids, glycerol, and $\beta$-hydroxybutyrate were measured. Energy balance was calculated from daily feed intake and milk yield, weekly body weight, and monthly milk component measurements. Adipose tissue biopsies were taken $21 \mathrm{~d}$ before expected parturition $(-21 \mathrm{~d})$ and at 5,21 , and 150 d postpartum. Semiquantitative Western blotting was used to measure abundance of hormone-sensitive lipase (HSL), phosphorylated HSL, perilipin, phosphorylated perilipin (PPLIN), adipose triglyceride lipase (ATGL), and comparative gene identity-58 (CGI-58). Abundance of ATGL was less at 5 and $21 \mathrm{~d}$ in milk (DIM) compared with -21 and 150 DIM, even though cows were in negative energy balance and experiencing increased rates of lipolysis in early lactation. In contrast, phosphorylated HSL and PPLIN increased with increasing lipolysis immediately after parturition. Additionally, PPLIN was negatively correlated with milk yield at 5 , 21, and $150 \mathrm{~d}$ postpartum, and negatively correlated with feed intake and energy balance at $21 \mathrm{~d}$ postpartum. This result is consistent with the hypothesis that phosphorylation of perilipin is responsive to signals for increased triaclyglyceride mobilization. Finally, a consistent negative correlation between abundance of perilipin and CGI-58 proteins was observed throughout
\end{abstract}

Received August 27, 2010.

Accepted January 7, 2011.

${ }^{1}$ Corresponding author: moodyd@iastate.edu the transition period. These results confirm that novel lipolytic proteins in adipose tissue are regulated at the level of protein abundance and phosphorylation during the periparturient period and into mid lactation.

Key words: perilipin, adipose triglyceride lipase, transition period, energy balance

\section{INTRODUCTION}

Milk production per cow has doubled over the last 40 yr, resulting in increased energy requirements throughout lactation (AIPL, 2010). It is widely recognized that energy demands due to the initiation of milk synthesis in early lactation are often not met by energy intake, causing cows to experience negative energy balance. Although a period of negative energy balance is a natural part of the lactation cycle, severe and prolonged negative energy balance can contribute to declines in fitness traits, including fertility (Veerkamp et al., 2000; Lopez et al., 2005), udder health (Banos et al., 2006), locomotive problems (Collard et al., 2000), and disease susceptibility (Hammon et al., 2006; van Knegsel et al., 2007).

During times of negative energy balance, mobilization of energy reserves from adipose tissue is a primary mechanism by which dairy cows compensate for their energy deficit. It is well established that activation of hormone-sensitive lipase (HSL) via protein kinase A (PKA) is a critical pathway in the regulation of lipolysis. More recently, additional proteins have been associated with lipolytic regulation (Figure 1). Perilipin (PLIN) is a phosphoprotein that associates with lipid droplets. In the basal state, PLIN protects the lipid droplet from HSL-mediated lipolysis (Brasaemle et al., 2000) and co-localizes with the protein comparative gene identity-58 (CGI-58; Subramanian et al., 2004; Yamaguchi et al., 2006). The phosphorylation of PLIN by PKA stimulates a conformational change in PLIN that provides HSL access to the lipid droplet and facilitates the interaction between HSL and its lipid substrate (Miyoshi et al., 2006). Additionally, phosphorylation of PLIN results in the release of CGI-58 from the lipid droplet. When CGI-58 is not associated with PLIN, it acts as an activator of adipose triglyceride 


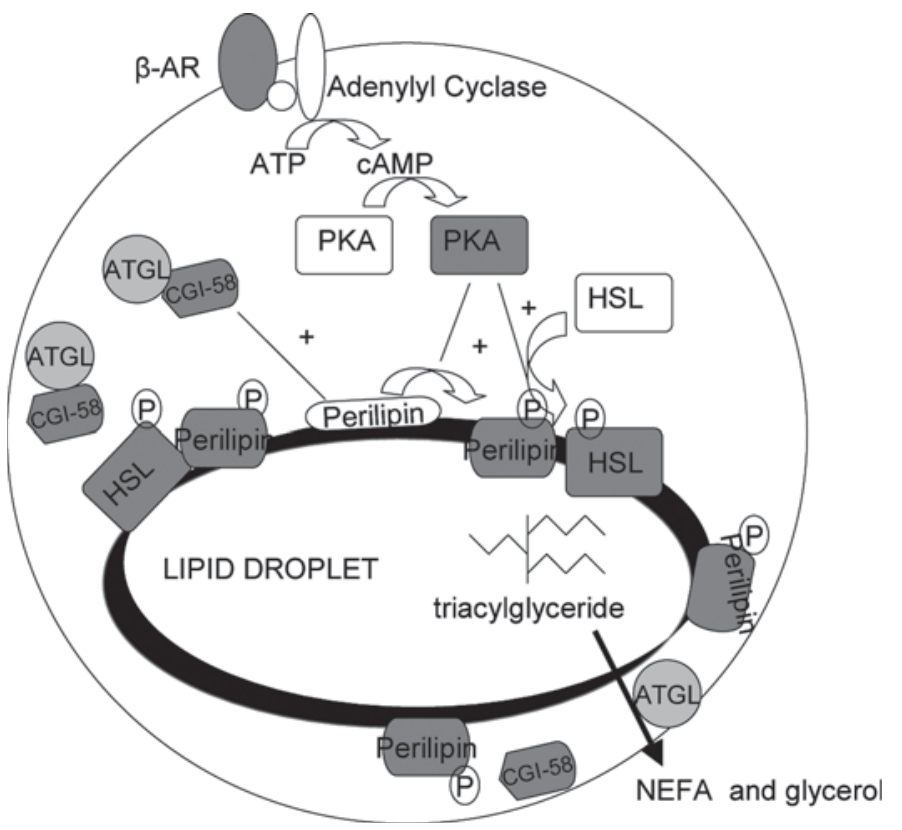

Figure 1. Working model of lipolysis. Beta-adrenergic receptors $(\beta-\mathrm{AR})$ are activated by the binding of catecholamines. This stimulation results in activation of adenylyl cyclase, which converts ATP to cyclic AMP (cAMP). Increased intracellular concentration of cAMP activates protein kinase A (PKA), which phosphorylates hormonesensitive lipase (HSL) and perilipin. Phosphorylated HSL translocates to the lipid droplet to hydrolyze triacylglycerides to free fatty acids (FFA) and glycerol. Phosphorylation of perilipin (1) facilitates interactions between phosphorylated HSL and its lipid substrate, and (2) releases comparative gene identity-58 (CGI-58) from the lipid droplet. Then, CGI-58 translocates to the cytosol where it interacts with adipose triglyceride lipase (ATGL). The translocation of ATGL to the lipid droplet allows for the hydrolysis of triacylglycerides to diacylglycerides. Lines with + represent a positive action, a circled ' $\mathrm{P}$ ' represents a phosphorylation event, and dark gray shapes represent active proteins.

lipase (ATGL) in the cytosol. The lipase ATGL can then translocate to the lipid droplet where it hydrolyzes triacylglycerides to diacylglycerides (Granneman et al., 2007; Schweiger et al., 2008; Figure 1). It has been suggested that the hydrolysis of triacylglycerides to diacylglycerides by ATGL is the rate-limiting step in lipolysis (Haemmerle et al., 2006), and that phosphorylation of PLIN is a "master regulator" of lipolysis through its control of both HSL and ATGL, with the latter mediated by CGI-58 (Moore et al., 2005; Miyoshi et al., 2007).

Appropriate regulation of lipolysis is critical for dairy cows to maintain health and productivity in times of negative energy balance. However, the coordinated regulation of HSL, PLIN, ATGL, and CGI-58 has not yet been studied in cattle. Thus, the current research was undertaken to determine if these proteins are altered at the level of protein abundance or phosphorylation with the changing metabolic demands of lactation. First, we quantified changes in protein abundance of HSL,
PLIN, ATGL, and CGI-58, as well as phosphorylation of HSL and PLIN, over the transition period. Second, we defined the relationship of these lipolytic proteins with traits influencing energy balance. Finally, we identified correlated changes among the lipolytic regulatory proteins.

\section{MATERIALS AND METHODS}

All procedures involving the use of animals were approved by the Iowa State University Institutional Animal Care and Use Committee.

\section{Animals}

Individual feed intake was measured daily on 26 multiparous $(13,7$, and 6 cows in lactations 2,3 , and 4 , respectively) Holstein cows using the Calan Broadbent feeding system (American Calan, Northwood, NH). Feed intake was measured from approximately $30 \mathrm{~d}$ before parturition through 150 DIM. Precalving and lactating cows were fed once or twice daily, respectively, and orts were removed and weighed daily. Cows were provided ad libitum access to a consistent TMR formulated to meet or exceed dry or lactating cow nutritional requirements (NRC, 2001). Lactating and nonlactating cows were weighed weekly following their morning milking and in early afternoon, respectively. Body condition scores were determined weekly using a 1 to 5 scale (Elanco, 1996).

\section{Milk Production and Milk Components}

Cows were milked twice daily with milk yield recorded at each milking. The software program Bestpred (Cole et al., 2009) was used to predict daily milk fat and protein percentages based on monthly DHIA testday results. Additional milk samples were taken at the morning milking and analyzed for lactose content by a commercial laboratory (Dairy Lab Services, Dubuque, IA).

\section{Blood and Tissue Sample Collection}

Blood was collected weekly via jugular venipuncture beginning at approximately $21 \mathrm{~d}$ before parturition through 28 DIM, and again at the completion of the study, at approximately 150 DIM. Serum was stored at $-80^{\circ} \mathrm{C}$ until future analysis. Serum glycerol concentrations were measured using Free Glycerol Reagent (F6428, Sigma Aldrich, St. Louis, MO) according to the manufacturer's protocol. Concentrations of NEFA and BHBA were analyzed from serum using commercially available kits according to the manufacturer's protocol 
(NEFA and Ranbut assay kits, respectively, Randox Laboratories, Co. Antrim, N. Ireland, UK).

Subcutaneous adipose tissue was collected from the tailhead region using a minimally invasive procedure. Briefly, the tailhead region was shaved and cleaned before administration of local anesthetic (2\% lidocaine). Following standard surgical preparation, a straight-line incision (approximately $3 \mathrm{~cm}$ ) was made. Tissue was excised using forceps and scalpel blade, and incisions were closed using surgical staples. With multiple sampling from each cow, samples were taken from alternating sides of the cow and only from areas devoid of scar tissue. Four 1-g samples of adipose tissue were collected at each biopsy. Biopsies were taken from each cow at 8 to $31 \mathrm{~d}$ prepartum $(-21$ DIM; $\mathrm{n}=26), 5$ to 9 DIM (5 DIM; $\mathrm{n}=26$ ), 21 to 31 DIM (21 DIM; $\mathrm{n}=26$ ), and 151 to 161 DIM (150 DIM; $\mathrm{n}=21$ ). Adipose tissue was immediately frozen in liquid nitrogen and stored at $-80^{\circ} \mathrm{C}$ until protein analysis.

\section{Semiquantitative Western Blotting}

Semiquantitative Western blotting assays were optimized for each protein of interest to validate linearity of detection for the range of protein abundance for each protein of interest. Proteins were extracted from adipose tissue samples and prepared for Western blotting as described previously (Elkins and Spurlock, 2009). Protein concentrations were determined by bicinchoninic assay (BCA; Pierce Protein Research, Rockford, IL) and used to standardize the quantity of total protein loaded on each gel. Proteins (10 to $400 \mu \mathrm{g}$ per lane, depending on protein of interest) were separated overnight through $10 \%$ [for detection of phosphorylated PLIN (PPLIN)] or $8 \%$ (for detection of all other proteins) SDS-PAGE gels, and transferred to polyvinylidene fluoride membranes. Membranes were incubated with the following primary antibodies: PLIN (AB10200, 1:1,000; Chemicon, Billerica, MA), PPLIN (AB10200, 1:5,000; Chemicon), HSL (4107, 1:1,000; Cell Signaling Technology, Beverly, MA), phosphorylated HSL (PHSL) at Ser 563 (4139, 1:500; Cell Signaling), ATGL (2138, 1:500; Cell Signaling), and CGI-58 (EB07657, 1:200; Everest Biotech, Upper Heyford, UK). Following incubation with secondary antibody [anti-goat IgG horseradish peroxidase-linked whole antibody from Santa Cruz Biotechnology (Santa Cruz, CA) for CGI-58, or anti-rabbit IgG horseradish peroxidase-linked whole antibody from GE Healthcare (Pittsburgh, PA) for all other proteins], proteins were detected using the ECL Plus Western Detection Kit (Amersham, Pittsburgh, PA) and imaged with Alpha Innotech Imager (FluorChem FC2, Cell Biosciences, Santa Clara, CA). Detected protein band areas were quantified using Totallab software for
1D analysis (TL100, v2009; Totallab Ltd., Newcastle upon Tyne, UK). All samples were run on duplicate gels. Protein abundance was normalized to abundance of the protein of interest quantified from a standard. The standard was an arbitrarily chosen sample that was loaded in lanes flanking samples from each cow on each gel. Normalization was achieved by subtracting the average standard protein abundance (measured in 2 lanes) from each sample. Normalized protein abundance was averaged across duplicate gels, and a constant was added to the normalized value of each sample for ease of statistical analysis and interpretation. For PPLIN, only the phosphorylated band (upper band) was used for data analysis.

\section{Energy Balance Calculations}

Net energy balance was predicted using published equations (NRC, 2001). Samples of the TMR were collected from a minimum of 3 feedings per week, pooled, and analyzed by a commercial laboratory (Dairyland Laboratories, Arcadia, WI) using wet chemistry. Net energy for lactation of the TMR was determined using equations of Weiss (1988) for cows at 3 multiples of maintenance. Net energy of feed intake $\left(\mathrm{NE}_{\mathrm{I}}\right)$ was calculated as the product of daily feed intake $(\mathrm{kg}), \mathrm{DM}$ percentage of the TMR, and $\mathrm{NE}_{\mathrm{L}}$ of the TMR. Daily feed intake was the average intake over 3 consecutive days within $3 \mathrm{~d}$ of tissue collection of lactating cows, or within $7 \mathrm{~d}$ of tissue collection for nonlactating cows. The $\mathrm{NE}_{\mathrm{L}}$ was calculated as $[(0.0929 \times$ fat $\%+0.0563 \times$ $\mathrm{CP} \%+0.0395 \times$ lactose $\%) \times \mathrm{kg}$ of milk yield] using the average of $3 \mathrm{~d}$ of actual milk yield (tissue collection day $\pm 1 \mathrm{~d}$ ), fat and protein percentages predicted from the Bestpred program (Cole et al., 2009) for the day of tissue collection, and the average of 2 lactose percentage estimates from samples collected within 4 $\mathrm{d}$ before and after the day of tissue collection. Net energy for maintenance was estimated as $\left[0.08 \times\left(\mathrm{BW}^{0.75}\right.\right.$, $\mathrm{kg})$. Body weight was the average of 2 measurements, taken within $1 \mathrm{wk}$ before and after the day of tissue collection. For energy balance estimates at 5 DIM, BW represented the first weight measured after the tissue collection day if the previous week's weight was taken before calving. Net energy of pregnancy $\left(\mathrm{NE}_{\mathrm{P}}\right)$ was estimated as $[(0.00318 \times \mathrm{d}$ of gestation -0.0352$) \times($ calf birth weight/45)]/0.218. Energy balance for lactating cows was calculated as $\mathrm{NE}_{\mathrm{I}}-\left(\mathrm{NE}_{\mathrm{M}}+\mathrm{NE}_{\mathrm{L}}\right)$, and for nonlactating cows as $\mathrm{NE}_{\mathrm{I}}-\left(\mathrm{NE}_{\mathrm{M}}+\mathrm{NE}_{\mathrm{P}}\right)$.

\section{Data Analysis}

All data were tested for normality and homoscedasticity using the Shapiro-Wilk and Levene tests, respec- 
A

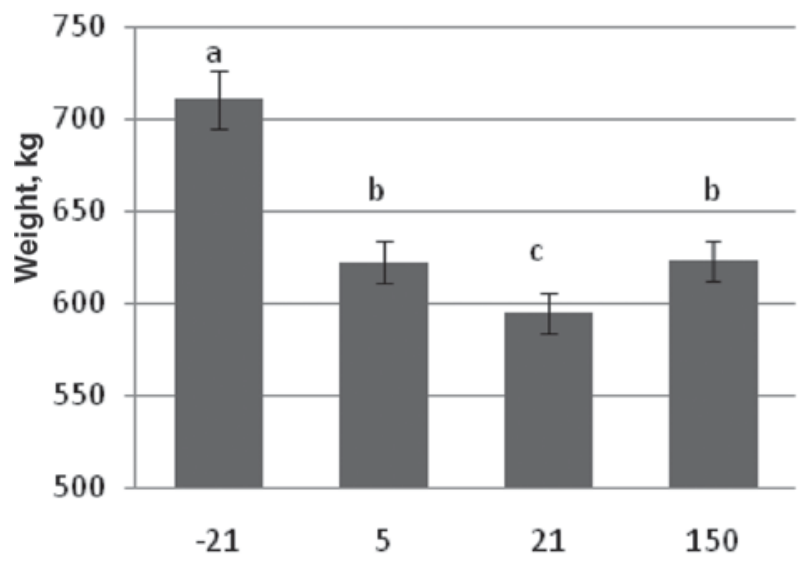

B

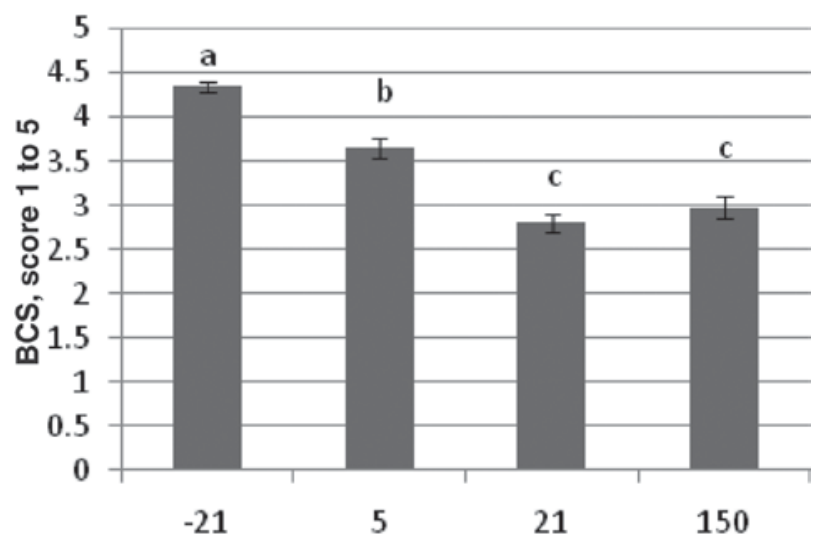

\section{C}

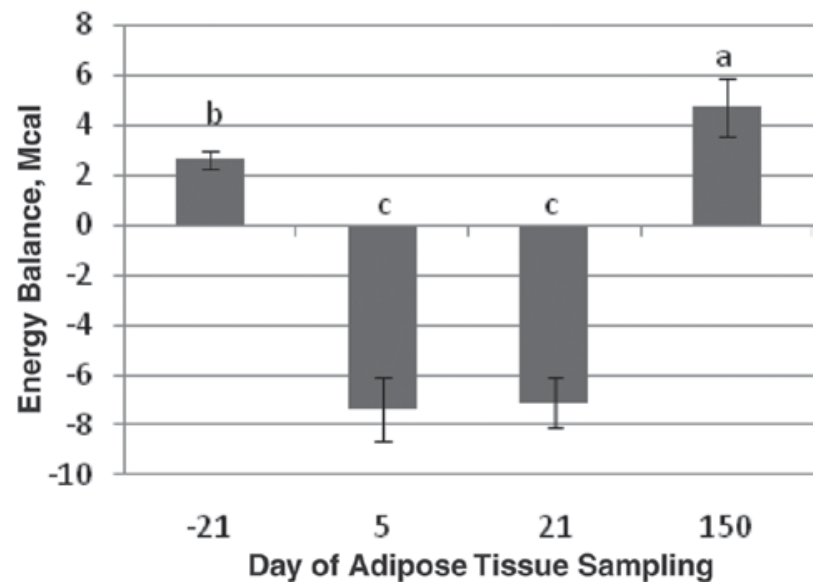

Figure 2. Body weight, BCS, and energy balance at the time of adipose tissue biopsy: (A) BW was measured weekly beginning approximately $30 \mathrm{~d}$ before calving through 150 DIM; BW around the time of biopsy was a single weight $\pm 3 \mathrm{~d}$ of the adipose tissue biopsy; (B) BCS was measured weekly beginning approximately $30 \mathrm{~d}$ before calving through 150 DIM; BCS around the time of biopsy was a single weight $\pm 3 \mathrm{~d}$ of the adipose tissue biopsy; (C) energy balance was calculated from feed intake calculated from daily amounts fed and refused, milk production, and milk components. Different letters indicate differences among means, $P<0.05$. tively (SAS Institute, 1999). Serum metabolite data were nonnormally distributed and lacked homoscedasticity and were transformed using the natural log-transformation $\left(\log _{\mathrm{e}}\right)$ to achieve normality. Abundance of HSL and PHSL were also nonnormally distributed. Multiple transformations were evaluated but none resulted in a normal distribution. The $\log _{\mathrm{e}}$ transformation was used for analysis of these proteins, because the mixed model analysis failed to converge when nontransformed data were used. Results of the mixed model analysis were confirmed using the Kruskal-Wallis test (SAS Institute, 1999; results not shown). Differences among biopsy days were determined using the mixed model methodology with repeated measures in SAS (SAS Institute, 1999). Adipose tissue biopsy day, or week of blood sampling were classified as categorical fixed effects, and cow was included in the model as a random factor. Day or week of sampling was the random factor. Alternate covariance structures were tested, and compound symmetry (CS), unstructured (UN), or heterogeneous first-order autoregressive structure (ARH) resulted in models with the best fit. Correlations were determined using PROC CORR in SAS (SAS Institute, 1999). Nonparametric Spearman correlations were calculated for all correlations involving transformed variables (NEFA, glycerol, HSL, PHSL). For correlations between protein and metabolite data, metabolite data were used if collected within $3 \mathrm{~d}$ of the adipose tissue biopsy.

\section{RESULTS}

Milk production based on 305-d mature-equivalent yield for the completed lactation encompassing the experiment averaged 14,025 kg. As expected, cows utilized body energy reserves with the onset of lactation, as indicated by decreased BW $(P<0.0001$; Figure 2a) and BCS $(P<0.0001 ;$ Figure 2b). Energy balance differed significantly across biopsy days, with cows experiencing negative energy balance at 5 and 21 DIM (Figure 2c).

Serum concentrations of NEFA, glycerol, and BHBA were evaluated as indicators of lipolysis. Serum NEFA concentrations differed significantly during sampling $(P<0.0001$; Figure 3a). Increased NEFA concentrations were observed $1 \mathrm{wk}$ before calving through $3 \mathrm{wk}$ postpartum. Similarly, glycerol concentrations differed during the sampling period $(P<0.0001$; Figure $3 \mathrm{~b}$. $)$ Elevated glycerol concentrations were observed at calving and 1 wk postpartum. Serum BHBA concentrations were increased at calving relative to other weeks evaluated (Figure 3c).

\section{Lipid Droplet-Associated Proteins}

The protein abundance of ATGL differed significantly over the sampling period $(P<0.0001)$, with decreased 
A

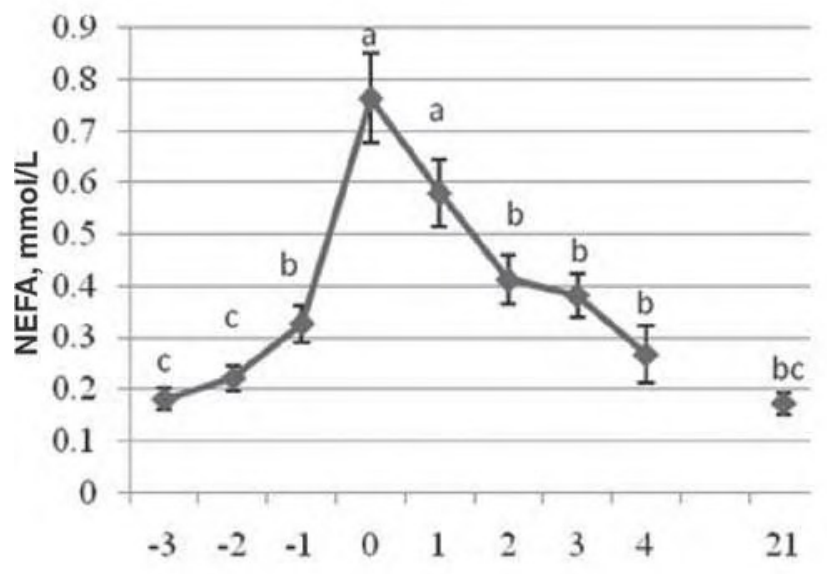

B
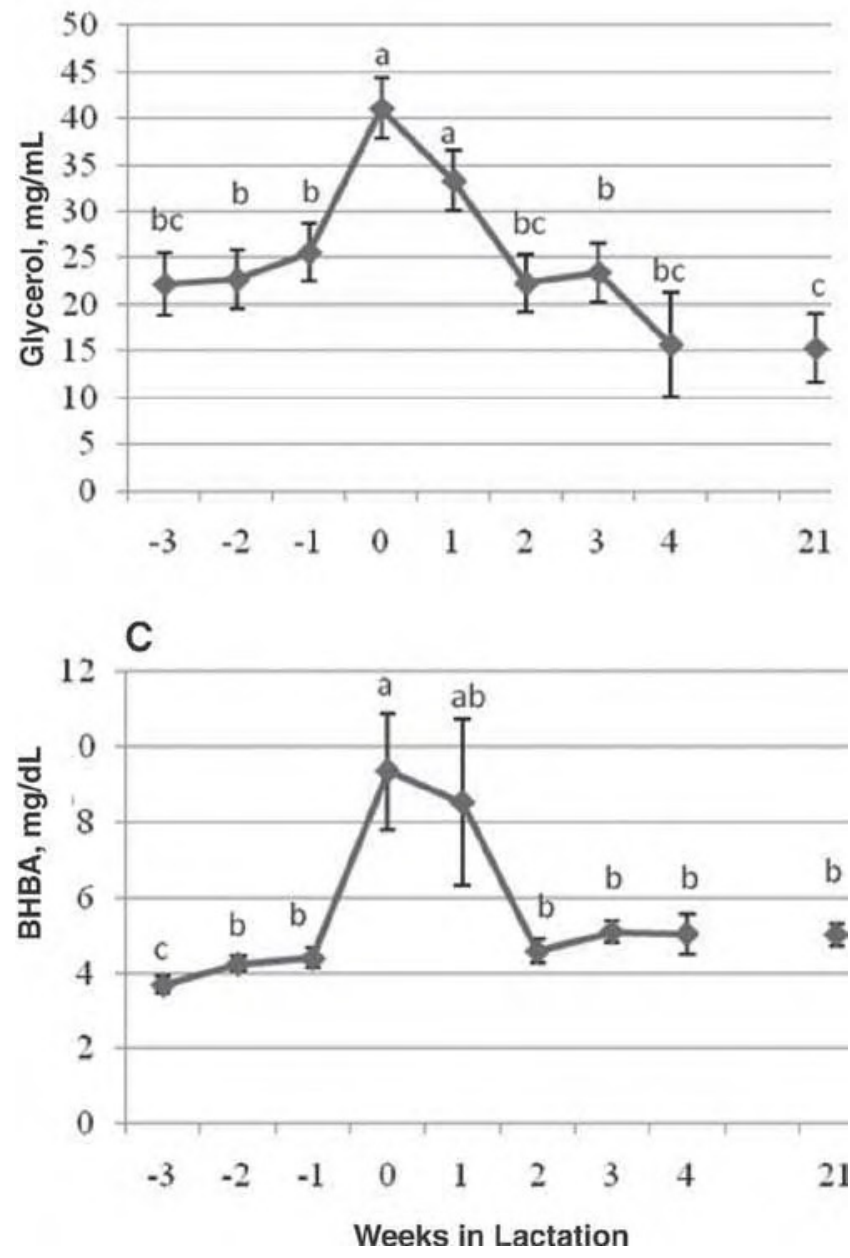

Figure 3. Circulating concentrations of NEFA (A), glycerol (B), and BHBA (C) at the time of adipose tissue biopsy. All circulating metabolites were measured weekly during the early afternoon. Weekly measurements of metabolites were from a single blood collection. Following collection, serum was separated and stored at $-80^{\circ} \mathrm{C}$ until analysis. Data were analyzed following natural log-transformation, but are presented on the linear scale for ease of interpretation. Different letters indicate differences among means, $P<0.05$. abundance observed at 5 and 21 DIM relative to precalving and 150 DIM. Abundance of HSL $(P=0.43)$, PLIN $(P=0.71)$, and CGI-58 $(P=0.13)$ did not differ among sampling times, although a numerical trend was observed for increasing CGI-58 with stage of lactation. Phosphorylation of HSL $(P=0.02)$ and PLIN $(P=$ $0.07)$ increased with the onset of lactation. Phosphorylation of HSL was similar precalving and at 150 DIM and was elevated at 5 and 21 DIM. Phosphorylated PLIN was significantly elevated at 5 DIM relative to 150 DIM $(P=0.01)$, with intermediate levels observed precalving and at 21 DIM (Figure 4).

\section{Correlations Between Lipolytic Indicators and Regulatory Proteins}

Correlations were calculated to evaluate the relationship between lipolytic indicators and proteins of interest. As expected, a significant $(P<0.05)$ correlation was found for NEFA with PPLIN, PHSL, and ATGL (r $=0.247,0.372$, and -0.376 , respectively). Additionally, significant correlations were observed for milk yield on the day of biopsy with PPLIN and PHSL $(\mathrm{r}=-0.310$ and -0.262 , respectively), for DMI with PPLIN ( $\mathrm{r}=$ -0.292 ), and for energy balance with PHSL and ATGL $(\mathrm{r}=-0.293$ and 0.359 , respectively. Because these correlations may reflect changes across biopsies, correlations were also calculated within biopsy day. Within biopsy day, correlations between NEFA and proteins of interest were not significant. The correlation between milk yield on the day of biopsy with PPLIN was significant at both 5 and 21 DIM, but with PHSL was only significant at 150 DIM. Correlations of milk yield with HSL at 150 DIM and with PPLIN at 150 DIM showed a statistical trend $(P<0.10)$. Dry matter intake was significantly correlated with PPLIN at 21 DIM and with PHSL before calving. The correlation with ATGL or PHSL with energy balance was nonsignificant when analyzed within biopsy day. Energy balance was also correlated with total PLIN abundance at 150 DIM (Tables 1 and 2).

\section{Correlations Among Lipolytic Proteins}

Analysis of all data revealed a positive correlation between PLIN and HSL $(\mathrm{r}=0.259, P=0.010)$. Perilipin and HSL were negatively correlated with CGI-58 $(\mathrm{r}=-0.448, P<0.001$ and $\mathrm{r}=-0.274, P=0.006$, respectively). Phosphorylation of PLIN and HSL were also correlated $(\mathrm{r}=0.420, P<0.001)$. Analysis within biopsy revealed a consistent negative correlation between PLIN and CGI-58 at 5, 21, and 150 DIM. Phosphorylated PLIN was positively correlated with PHSL prepartum, and with ATGL at 5 DIM. Finally, ATGL 
was significantly correlated with PHSL prepartum (Tables 3 and 4).

\section{DISCUSSION}

In this study, we describe changes in abundance of lipid droplet-associated proteins over the transition period and the in vivo coordination of these proteins with energy balance and lipolytic indicators. Three important findings provide novel insight regarding the regulation of these proteins throughout the transition period. First, ATGL protein abundance decreased with the onset of lactation. Second, significant associations between PLIN and energy balance were observed, and third, changes in abundance of PLIN and CGI-58 proteins were coordinately regulated.

Adipose triglyceride lipase was initially identified after HSL knockout mice maintained normal lipolysis and body composition (Jenkins et al., 2004; Villena et al., 2004; Zimmermann et al., 2004). Since then, ATGL has been described as a rate-limiting step of lipolysis (Haemmerle et al., 2006). Abundance of ATGL increases in response to caloric restriction and glucocorticoids (Villena et al., 2004; Deiuliis et al., 2008), suggesting that protein abundance increases in response to a greater need for lipolytic mobilization of energy due to metabolic or pharmacologic stimuli. Thus, in the current study, we expected increased abundance of ATGL at 5 and 21 DIM, when rates of lipolysis were greatest. Surprisingly, a clear and consistent decrease in ATGL was observed at these time points. One potential explanation for this unexpected result is the relative importance of ATGL during times of basal versus PKAmediated lipolysis. It is well documented that ATGL is necessary for both basal and stimulated lipolysis in 3T3-L1 adipocytes and rodent models (Haemmerle et al., 2006; Granneman et al., 2007; Miyoshi et al., 2008). However, results from experiments using human adipocytes indicate that ATGL is less important than HSL in regulating PKA-mediated lipolysis, whereas both participate in basal lipolysis (Langin et al., 2005, Rydén et al., 2007). Additionally, ATGL but not HSL or PLIN regulates lipid droplet size under basal conditions in adipocytes derived from mouse embryonic fibroblasts (Miyoshi et al., 2008). Our observation that ATGL abundance is significantly less during negative versus positive energy balance potentially reflects a shift from ATGL-dependent basal lipolysis during positive energy balance to HSL-dependent PKA-stimulated lipolysis during negative energy balance. Furthermore, we hypothesize that this downregulation of ATGL at the onset of lactation may protect the cow from a potentially detrimental depletion of lipid stores if both lipases were coordinately upregulated. This hypothesis is supported
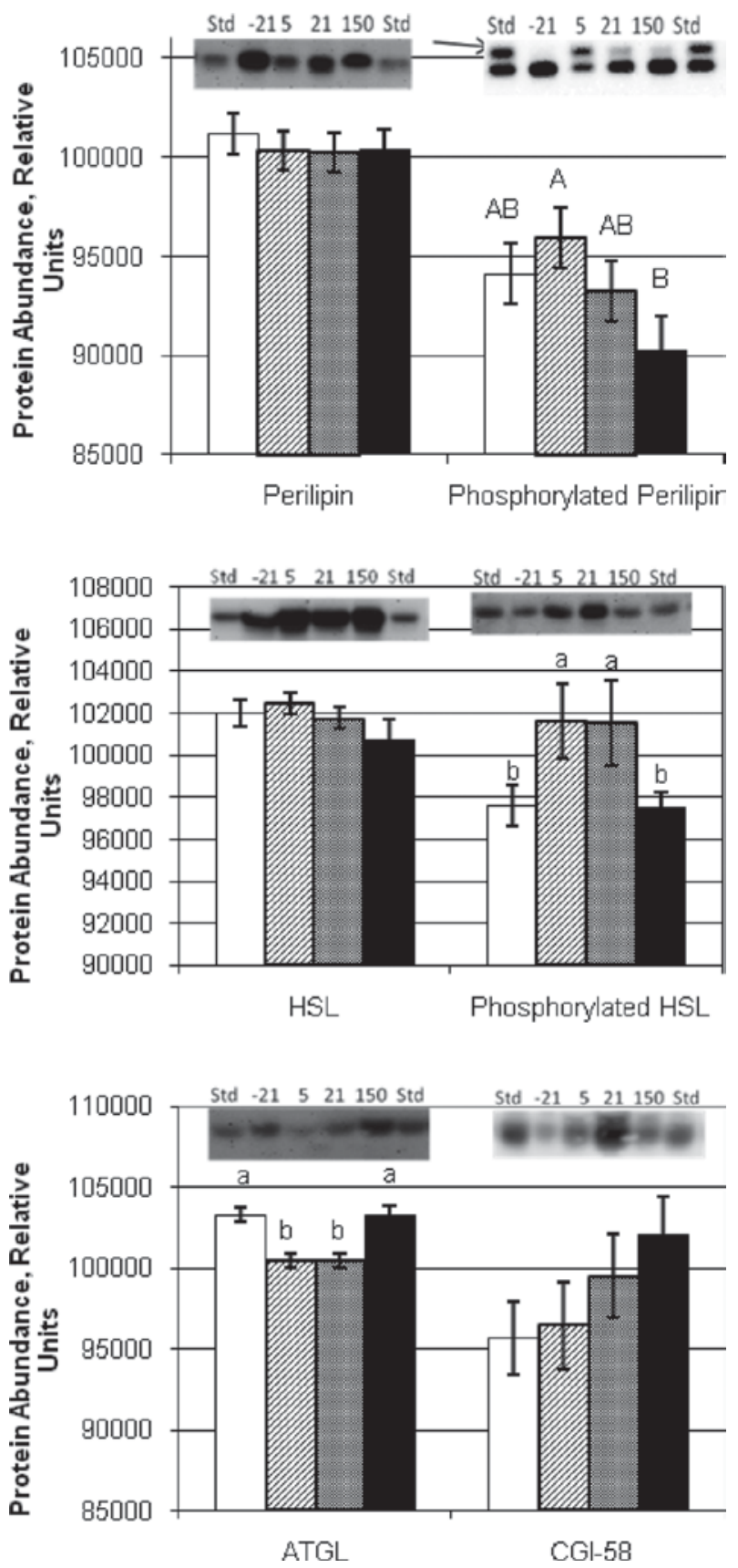

Figure 4. Protein abundance of total and phosphorylated lipid droplet-associated proteins. Adipose tissue samples used for Western blotting were taken approximately $21 \mathrm{~d}$ before parturition (31 to 8), and 5 (4 to 9), 21 (21 to 31), and 150 (151 to 161) DIM. Protein abundance of adipose triglyceride lipase (ATGL), hormone-sensitive lipase (HSL), perilipin, comparative gene identity-58 (CGI-58), phosphorylated perilipin, and Ser-563 phosphorylated HSL (phosphorylated HSL) was determined by semiquantitative Western blotting and expressed in relative units, normalized to a common standard. Each inset shows a representative Western blot, and the arrow indicates the band used for quantification of phosphorylated perilipin. Biopsy days are represented as follows: -21 , solid white; +5 DIM, diagonal stripe; +21 DIM, gray; +150 DIM, solid black. Lowercase and uppercase letters represent overall differences among means, $P<0.05$ and $P<0.1$, respectively. Different letters indicate differences among means, $P<$ 0.05 . 
Table 1. Correlation coefficients (r) between milk production traits and lipid droplet-associated protein abundance and phosphorylation

\begin{tabular}{|c|c|c|c|c|c|c|}
\hline \multirow[b]{2}{*}{ Protein $^{1}$} & \multicolumn{3}{|c|}{ Milk yield $^{2}$} & \multicolumn{3}{|c|}{ ECM yield ${ }^{2}$} \\
\hline & 5 DIM & 21 DIM & 150 DIM & 5 DIM & 21 DIM & 150 DIM \\
\hline PLIN & -0.006 & -0.255 & -0.079 & -0.142 & -0.222 & -0.297 \\
\hline $\mathrm{HSL}^{3}$ & 0.186 & -0.220 & $-0.428 \dagger$ & 0.017 & -0.137 & -0.335 \\
\hline PPLIN & $-0.459 *$ & $-0.419^{*}$ & $-0.431 \dagger$ & -0.251 & -0.097 & -0.090 \\
\hline PHSL $^{3}$ & -0.312 & -0.168 & $-0.556^{*}$ & $-0.331 \dagger$ & 0.064 & $-0.427 \dagger$ \\
\hline ATGL & 0.125 & 0.162 & -0.155 & 0.204 & 0.044 & -0.052 \\
\hline CGI-58 & -0.202 & -0.032 & 0.348 & -0.108 & 0.040 & 0.100 \\
\hline
\end{tabular}

${ }^{1}$ PLIN $=$ perilipin; HSL $=$ hormone-sensitive lipase; PPLIN = phosphorylated PLIN; PHSL = phosphorylated HSL; ATGL = adipose triglyceride lipase; CGI-58 = comparative gene identity-58.

${ }^{2}$ DIM: 5 DIM indicates proteins from adipose tissue biopsy taken 4 to 9 DIM; 21 DIM indicates adipose tissue biopsy taken 21 to 31 DIM; and 150 DIM indicates adipose tissue biopsy taken 151 to 161 DIM.

${ }^{3}$ Natural log-transformed data were analyzed using Spearman correlation.

$* P \leq 0.05 ; \dagger P<0.1$

by cell culture experiments, in which ATGL mRNA is downregulated by isoproterenol, forskolin, and cholera toxin (Kralisch et al., 2005). Potential mechanisms of ATGL regulation warrant further investigation in the transition dairy cow.

Because PLIN is a known phosphorylation target of PKA, we expected its phosphorylation to increase at 5 and 21 DIM. This trend was observed, and is consistent with our previous report describing the abundance of PPLIN in cows in early (5-14 DIM) versus late (176-206 DIM) lactation (Elkins and Spurlock, 2009). However, significant correlations between PPLIN and circulating NEFA and glycerol concentrations within stage of lactation described previously (Elkins and Spurlock, 2009) were not observed within biopsy day in the present study. Likewise, the significant correlations of PHSL with NEFA and glycerol were not observed in the present study. One possible explanation for this discrepancy is that the former study measured NEFA and glycerol from serum samples collected at the time of biopsy, whereas the current study used metabolite data from samples collected up to $3 \mathrm{~d}$ before or after the biopsy. The lack of correlation in this study may reflect rapidly changing concentrations of NEFA and glycerol, or transient changes in phosphorylation of PLIN, during early lactation. This explanation is supported by the fact that the correlation between PPLIN and glycerol at 150 DIM, when biopsy and serum samples were collected on the same day, tended toward significance $(\mathrm{r}=0.42 ; P=0.08$, data not shown) and was consistent with the correlation observed in late lactation cows in the previous study $(\mathrm{r}=0.65 ; P=0.06)$. Alternatively, NEFA and phosphorylated proteins may not be correlated in the current data because of differences in lipolytic rates among adipose tissue depots. In growing steers, increased lipolytic activity in subcutaneous compared with visceral adipose tissue depots was observed (Pothoven et al., 1975; Rule et al., 1992). However, a slightly higher lipolytic rate was observed in perirenal compared with subcutaneous adipose tissue of

Table 2. Correlation coefficients (r) between intake and energy balance, and lipid droplet-associated protein abundance and phosphorylation

\begin{tabular}{|c|c|c|c|c|c|c|c|c|}
\hline Protein $^{1}$ & \multicolumn{4}{|c|}{$\mathrm{DMI}^{2}$} & \multicolumn{4}{|c|}{ Energy balance $^{2}$} \\
\hline PLIN & -0.198 & -0.163 & -0.199 & 0.049 & -0.234 & 0.017 & 0.007 & $0.489^{*}$ \\
\hline PPLIN & -0.111 & -0.260 & $-0.482^{*}$ & -0.182 & 0.042 & 0.053 & $-0.408^{*}$ & -0.064 \\
\hline PHSL $^{3}$ & $-0.396^{*}$ & -0.203 & $-0.340 \dagger$ & $-0.417 \dagger$ & -0.210 & 0.039 & $-0.368 \dagger$ & 0.151 \\
\hline ATGL & -0.097 & -0.074 & 0.014 & -0.158 & 0.146 & -0.245 & 0.031 & -0.041 \\
\hline
\end{tabular}

${ }^{1}$ PLIN = perilipin; HSL = hormone-sensitive lipase; PPLIN = phosphorylated PLIN; PHSL = phosphorylated HSL; ATGL = adipose triglyceride lipase; CGI-58 = comparative gene identity-58

${ }^{2}$ DIM: -21 DIM indicates proteins from adipose tissue biopsy taken 31 to $8 \mathrm{~d}$ before parturition; 5 DIM indicates adipose tissue biopsy taken 4 to 9 DIM; 21 DIM indicates adipose tissue biopsy taken 21 to 31 DIM; and 150 DIM indicates adipose tissue biopsy taken 151 to 161 DIM.

${ }^{3}$ Natural log-transformed data were analyzed using Spearman correlation.

$* P \leq 0.05 ; \dagger P<0.1$. 
Table 3. Correlation coefficients ( $\mathrm{r}$ ) among lipid droplet-associated protein abundance determined by semiquantitative Western blotting from adipose tissue biopsies collected 4 to 9 DIM (above diagonal) and 21 to 31 DIM (below diagonal) ${ }^{1}$

\begin{tabular}{lcccccc}
\hline Protein & PLIN & HSL $^{2}$ & PPLIN & PHSL $^{2}$ & ATGL & \multicolumn{1}{c}{ CGI-58 } \\
\hline PLIN & & 0.279 & -0.246 & 0.205 & -0.086 & $-0.447^{*}$ \\
HSL $^{2}$ & 0.131 & & 0.228 & 0.145 & $0.400^{*}$ & -0.195 \\
PPLIN $_{\text {PHSL }}^{2}$ & 0.081 & -0.311 & & $0.385 \dagger$ & $0.476^{*}$ & -0.178 \\
ATGL & 0.101 & -0.004 & $0.350 \dagger$ & & 0.201 & 0.253 \\
CGI-58 & 0.039 & 0.039 & -0.137 & 0.186 & & -0.084 \\
\hline
\end{tabular}

${ }^{1}$ PLIN = perilipin; HSL = hormone-sensitive lipase; PPLIN = phosphorylated PLIN; PHSL = phosphorylated HSL; ATGL = adipose triglyceride lipase; CGI-58 = comparative gene identity-58.

${ }^{2}$ Natural log-transformed data were analyzed using Spearman correlation.

$* P \leq 0.05 ; \dagger P<0.1$.

ewes (Etherton et al., 1977). Furthermore, lactation in sheep appears to alter the lipolytic response of adipose tissue to $\beta$-adrenergic stimulation via depot-specific mechanisms (Vernon et al., 1995). Thus, in the current data, variation in circulating NEFA concentrations may reflect differences in visceral lipolysis, whereas the measurement of protein phosphorylation is from subcutaneous adipose tissue.

Despite the lack of a significant relationship between PPLIN and NEFA within biopsy day, significant correlations between PPLIN and milk yield, DMI, and energy balance were observed in early lactation. Although cause and effect cannot be determined from correlative data, these results are consistent with the hypothesis that PPLIN plays an important role in energy utilization in vivo. The negative correlation between PPLIN and milk yield is particularly intriguing. A positive relationship would have supported the hypothesis that increased energy mobilization through phosphorylation of PLIN supported higher milk production. In contrast, it seems that PLIN may be phosphorylated in response to a signal for increased energy mobilization when milk yield is limited by energy availability. Initially (at 5 DIM), only the relationship between milk yield and PPLIN was evident. However, by 21 DIM, it appeared that increased PPLIN was associated with cows experiencing more severe negative energy balance due to insufficient feed intake that was ultimately limiting the cow's milk production. Thus, the combination of milk yield and feed intake, rather than either of these alone, may contribute to variation in PPLIN. However, further research is needed to test this hypothesis and define the mechanisms responsible for the observed correlations.

In addition to the correlation with PPLIN in early lactation, total PLIN protein abundance was positively correlated with energy balance at 150 DIM. This correlation may reflect increasing adiposity and lipid droplet formation with increasing energy balance at 150 DIM. Perilipin was not correlated with BCS at this time point, but the subjective visual evaluation of BCS may have lacked the sensitivity to detect early changes in adiposity. Alternatively, variation in PLIN in the single adipose tissue depot sampled may not be reflective of overall body composition. Regardless, the biological relevance of the correlation between PLIN and energy balance in mid lactation warrants further investigation.

Finally, PLIN protein abundance was negatively correlated with CGI-58 at all sampling times. To our knowledge, this is the first report of coordinated regula-

Table 4. Correlation coefficients ( $\mathrm{r}$ ) among lipid droplet-associated protein abundance determined by semiquantitative Western blotting from adipose tissue biopsies collected 31 to $8 \mathrm{~d}$ before parturition (above diagonal) and 151 to 161 DIM (below diagonal) ${ }^{1}$

\begin{tabular}{lrrrrrr}
\hline Protein & PLIN & \multicolumn{1}{c}{ HSL $^{2}$} & PPLIN & PHSL $^{2}$ & ATGL & \multicolumn{1}{c}{ CGI-58 } \\
\hline PLIN & & 0.252 & 0.050 & 0.182 & $0.363 \dagger$ & -0.329 \\
HSL $^{2}$ & 0.353 & & 0.291 & -0.041 & 0.097 & -0.291 \\
PPLIN $^{2}$ & 0.117 & -0.016 & & $0.443^{*}$ & 0.223 & 0.016 \\
PHSL $^{2}$ & 0.345 & 0.049 & 0.346 & & $0.394^{*}$ & -0.230 \\
ATGL & -0.168 & 0.122 & -0.016 & -0.025 & & -0.129 \\
CGI-58 & $-0.523^{*}$ & -0.316 & -0.290 & -0.123 & 0.252 & \\
\hline
\end{tabular}

${ }^{1}$ PLIN $=$ perilipin; HSL $=$ hormone-sensitive lipase; PPLIN $=$ phosphorylated PLIN; PHSL $=$ phosphorylated HSL; ATGL = adipose triglyceride lipase; CGI-58 = comparative gene identity-58.

${ }^{2}$ Natural log-transformed data were analyzed using Spearman correlation.

$\dagger P<0.1 ;{ }^{*} P \leq 0.05$. 
tion of these proteins in any model. Although expression of PLIN is known to be responsive to peroxisome proliferator-activated receptor- $\gamma$ (Shimizu et al., 2006), estrogen receptor-related receptor (Akter et al., 2008), and RAR-related orphan receptor (ROR)- $\alpha$ (Ohoka et al., 2009), little is known about the regulation of CGI58. However, expression of PLIN mRNA and protein is specific to adipocytes (Greenberg et al., 1991), whereas CGI-58 is expressed in both preadipocytes and adipocytes (Yamaguchi et al., 2007). Therefore, the negative relationship between perilipin and CGI-58 may, in part, reflect variation in abundance of preadipocytes versus mature adipocytes in the adipose tissue sampled.

\section{CONCLUSIONS}

Proteins involved in the regulation of lipolysis are dynamically regulated throughout the transition period of multiparous Holstein cows. Although ATGL is often described as the rate-limiting step of lipolysis in other species, we show that it is dramatically downregulated at the onset of lactation when the demand for lipolysis is greatest. In contrast, changes in phosphorylation of PLIN and HSL reflect changes in lipolysis across the time points sampled. Additionally, PPLIN is negatively correlated with milk yield, DMI, and energy balance at 21 DIM, potentially reflecting a complex response to multiple signals of energy demands. Finally, the protein abundances of PLIN and CGI-58 appear to be closely coordinated throughout lactation. Together, these results demonstrate that the abundance of ATGL and phosphorylation of HSL and PLIN are altered throughout the transition period and potentially contribute to the homeorhetic response to the onset of lactation.

\section{ACKNOWLEDGMENTS}

This project was supported by National Research Initiative Competitive Grant no. 2009-35206-05222 from the USDA Cooperative State Research, Education, and Extension Service. The authors also acknowledge S. M. Lonergan (Iowa State University, Ames) for technical support in protein detection.

\section{REFERENCES}

AIPL. 2010. Trend in milk BV for Holstein or Red and White. Vol. 2010. Animal Improvement Programs Laboratory, Beltsville, MD.

Akter, M. H., T. Yamaguchi, F. Hirose, and T. Osumi. 2008. Perilipin, a critical regulator of fat storage and breakdown, is a target gene of estrogen receptor-related receptor alpha. Biochem. Biophys. Res. Commun. 368:563-568.

Banos, G., M. P. Coffey, E. Wall, and S. Brotherstone. 2006. Genetic relationship between first-lactation body energy and later-life udder health in dairy cattle. J. Dairy Sci. 89:2222-2232.

Brasaemle, D. L., B. Rubin, I. A. Harten, J. Gruia-Gray, A. R. Kimmel, and C. Londos. 2000. Perilipin A increases triacylglycerol storage by decreasing the rate of triacylglycerol hydrolysis. J. Biol. Chem. 275:38486-38493.

Cole, J. B., D. J. Null, and P. M. VanRaden. 2009. Best prediction of yields for long lactations. J. Dairy Sci. 92:1796-1810.

Collard, B. L., P. J. Boettcher, J. C. Dekkers, D. Petitclerc, and L. R. Schaeffer. 2000. Relationships between energy balance and health traits of dairy cattle in early lactation. J. Dairy Sci. 83:26832690 .

Deiuliis, J. A., J. Shin, D. Bae, M. J. Azain, R. Barb, and K. Lee. 2008. Developmental, hormonal, and nutritional regulation of porcine adipose triglyceride lipase (ATGL). Lipids 43:215-225.

Elanco. 1996. Body Condition Scoring in Dairy Cattle. Vol. Al 8478. Elanco Animal Health, Greenfield, IN.

Elkins, D. A., and D. M. Spurlock. 2009. Phosphorylation of perilipin is associated with indicators of lipolysis in Holstein cows. Horm. Metab. Res. 41:736-740.

Etherton, T. D., D. E. Bauman, and J. R. Romans. 1977. Lipolysis in subcutaneous and perirenal adipose tissue from sheep and dairy steers. J. Anim. Sci. 44:1100-1106.

Granneman, J. G.. H. P. Moore, R. L. Granneman, A. S. Greenberg, M. S. Obin, and Z. Zhu. 2007. Analysis of lipolytic protein trafficking and interactions in adipocytes. J. Biol. Chem. 282:5726-5735.

Greenberg, A. S., J. J. Egan, S. A. Wek, N. B. Garty, E. J. Blanchette-Mackie, and C. Londos. 1991. Perilipin, a major hormonally regulated adipocyte-specific phosphoprotein associated with the periphery of lipid storage droplets. J. Biol. Chem. 266:1134111346.

Haemmerle, G., A. Lass, R. Zimmermann, G. Gorkiewicz, C. Meyer, J. Rozman, G. Heldmaier, R. Maier, C. Theussl, S. Eder, D. Kratky, E. F. Wagner, M. Klingenspor, G. Hoefler, and R. Zechner. 2006. Defective lipolysis and altered energy metabolism in mice lacking adipose triglyceride lipase. Science 312:734-737.

Hammon, D. S., I. M. Evjen, T. R. Dhiman, J. P. Goff, and J. L. Walters. 2006. Neutrophil function and energy status in Holstein cows with uterine health disorders. Vet. Immunol. Immunopathol. 113:21-29.

Jenkins, C. M., D. J. Mancuso, W. Yan, H. F. Sims, B. Gibson, and R. W. Gross. 2004. Identification, cloning, expression, and purification of three novel human calcium-independent phospholipase A2 family members possessing triacylglycerol lipase and acylglycerol transacylase activities. J. Biol. Chem. 279:48968-48975.

Kralisch, S., J. Klein, U. Lossner, M. Bluher, R. Paschke, M. Stumvoll, and M. Fasshauer. 2005. Isoproterenol, TNFalpha, and insulin downregulate adipose triglyceride lipase in 3T3-L1 adipocytes. Mol. Cell. Endocrinol. 240:43-49.

Langin, D., A. Dicker, G. Tavernier, J. Hoffstedt, A. Mairal, M. Ryden, E. Arner, A. Sicard, C. M. Jenkins, N. Viguerie, V. van Harmelen, R. W. Gross, C. Holm, and P. Arner. 2005. Adipocyte lipases and defect of lipolysis in human obesity. Diabetes 54:3190-3197.

Lopez, H., D. Z. Caraviello, L. D. Satter, P. M. Fricke, and M. C. Wiltbank. 2005. Relationship between level of milk production and multiple ovulations in lactating dairy cows. J. Dairy Sci. $88: 2783-2793$

Miyoshi, H., J. W. Perfield 2nd, M. S. Obin, and A. S. Greenberg. 2008. Adipose triglyceride lipase regulates basal lipolysis and lipid droplet size in adipocytes. J. Cell. Biochem. 105:1430-1436.

Miyoshi, H., J. W. Perfield 2nd, S. C. Souza, W. J. Shen, H. H. Zhang, Z. S. Stancheva, F. B. Kraemer, M. S. Obin, and A. S. Greenberg. 2007. Control of adipose triglyceride lipase action by serine 517 of perilipin A globally regulates protein kinase A-stimulated lipolysis in adipocytes. J. Biol. Chem. 282:996-1002.

Miyoshi, H., S. C. Souza, H. H. Zhang, K. J. Strissel, M. A. Christoffolete, J. Kovsan, A. Rudich, F. B. Kraemer, A. C. Bianco, M. S. Obin, and A. S. Greenberg. 2006. Perilipin promotes hormonesensitive lipase-mediated adipocyte lipolysis via phosphorylation-dependent and -independent mechanisms. J. Biol. Chem. 281:15837-15844.

Moore, H. P., R. B. Silver, E. P. Mottillo, D. A. Bernlohr, and J. G. Granneman. 2005. Perilipin targets a novel pool of lipid droplets for lipolytic attack by hormone-sensitive lipase. J. Biol. Chem. 280:43109-43120. 
National Research Council. 2001. Nutrient Requirements of Dairy Cattle. 7th ed. Natl. Acad. Press, Washington, DC.

Ohoka, N., S. Kato, Y. Takahashi, H. Hayashi, and R. Sato. 2009. The orphan nuclear receptor RORalpha restrains adipocyte differentiation through a reduction of $\mathrm{C} / \mathrm{EBPbeta}$ activity and perilipin gene expression. Mol. Endocrinol. 23:759-771.

Pothoven, M. A., D. C. Beitz, and J. H. Thornton. 1975. Lipogenesis and lipolysis in adipose tissue of ad libitum and restricted-fed beef cattle during growth. J. Anim. Sci. 40:957-962.

Rule, D. C., J. H. Thornton, A. D. McGilliard, and D. C. Beitz. 1992. Effect of adipose tissue site, animal size, and fasting on lipolysis in bovine adipose tissue in vitro. Int. J. Biochem. 24:789-793.

Rydén, M., J. Jocken, V. van Harmelen, A. Dicker, J. Hoffstedt, M. Wiren, L. Blomqvist, A. Mairal, D. Langin, E. Blaak, and P. Arner. 2007. Comparative studies of the role of hormone-sensitive lipase and adipose triglyceride lipase in human fat cell lipolysis. Am. J. Physiol. Endocrinol. Metab. 292:E1847-E1855.

SAS Institute. 1999. SAS/STAT User's Guide. Version 6.12. SAS Institute Inc., Cary, NC.

Schweiger, M., G. Schoiswohl, A. Lass, F. P. Radner, G. Haemmerle, R. Malli, W. Graier, I. Cornaciu, M. Oberer, R. Salvayre, J. Fischer, R. Zechner, and R. Zimmermann. 2008. The C-terminal region of human adipose triglyceride lipase affects enzyme activity and lipid droplet binding. J. Biol. Chem. 283:17211-17220.

Shimizu, M., D. Yamashita, T. Yamaguchi, F. Hirose, and T. Osumi. 2006. Aspects of the regulatory mechanisms of PPAR functions: Analysis of a bidirectional response element and regulation by sumoylation. Mol. Cell. Biochem. 286:33-42.

Subramanian, V., A. Rothenberg, C. Gomez, A. W. Cohen, A. Garcia, S. Bhattacharyya, L. Shapiro, G. Dolios, R. Wang, M. P. Lisanti, and D. L. Brasaemle. 2004. Perilipin A mediates the reversible binding of CGI-58 to lipid droplets in 3T3-L1 adipocytes. J. Biol. Chem. 279:42062-42071. van Knegsel, A. T., G. de Vries Reilingh, S. Meulenberg, H. van den Brand, J. Dijkstra, B. Kemp, and H. K. Parmentier. 2007. Natural antibodies related to energy balance in early lactation dairy cows. J. Dairy Sci. 90:5490-5498.

Veerkamp, R. F., J. K. Oldenbroek, H. J. Van der Gaast, and J. H. Van der Werf. 2000. Genetic correlation between days until start of luteal activity and milk yield, energy balance, and live weights. J. Dairy Sci. 83:577-583.

Vernon, R. G., R. Doris, E. Finley, M. D. Houslay, E. Kilgour, and S. Lindsay-Watt. 1995. Effects of lactation on the signal transduction systems regulating lipolysis in sheep subcutaneous and omental adipose tissue. Biochem. J. 308:291-296.

Villena, J. A., S. Roy, E. Sarkadi-Nagy, K. H. Kim, and H. S. Sul. 2004. Desnutrin, an adipocyte gene encoding a novel patatin domain-containing protein, is induced by fasting and glucocorticoids: Ectopic expression of desnutrin increases triglyceride hydrolysis. J. Biol. Chem. 279:47066-47075.

Weiss, W. P. 1998. Estimating the available energy content of feeds for dairy cattle. J. Dairy Sci. 81:830-839.

Yamaguchi, T., N. Omatsu, E. Morimoto, H. Nakashima, K. Ueno, T. Tanaka, K. Satouchi, F. Hirose, and T. Osumi. 2007. CGI-58 facilitates lipolysis on lipid droplets but is not involved in the vesiculation of lipid droplets caused by hormonal stimulation. J. Lipid Res. 48:1078-1089.

Yamaguchi, T., N. Omatsu, A. Omukae, and T. Osumi. 2006. Analysis of interaction partners for perilipin and ADRP on lipid droplets. Mol. Cell. Biochem. 284:167-173.

Zimmermann, R., J. G. Strauss, G. Haemmerle, G. Schoiswohl, R. Birner-Gruenberger, M. Riederer, A. Lass, G. Neuberger, F. Eisenhaber, A. Hermetter, and R. Zechner. 2004. Fat mobilization in adipose tissue is promoted by adipose triglyceride lipase. Science $306: 1383-1386$ 